\title{
Las atarazanas de Málaga. Proyectos de intervención en el siglo XVIII
}

\author{
Rosario Camacho Martinez *
}

\section{INTRODUCCIÓN}

Después de la Guerra de Sucesión y a lo largo del siglo xvill las necesidades de alojamiento para la tropa van a ser una constante en toda España. A pesar de la planificación para la defensa del territorio que ya iniciaran Carlos $V$ y Felipe $I I$ y de las sucesivas contiendas que tuvieron lugar, tanto interiores como exteriores, la infraestructura de fortificaciones, cuarteles y almacenes era bastante deficiente. La necesidad de alojamiento para la tropa y de locales para el almacenamiento de los pertrechos militares llevó a tomar medidas y en $1717 \mathrm{~J}$. P. Verboom, publicaba un Proyecto sobre la construcción de cuarteles en todo el reino'.

Pero no siempre se contaba con los solares adecuados, los edificios aptos para su transformación o el dinero necesario para emprender las obras. Desde antiguo se gravaba a la población con las obligaciones de alojar soldados y contribuir a su manutención lo cual ocasionaba graves problemas sociales; se ocupaban las casas o almacenes particulares, con

Departamento de Historia del Arte. Universidad de Málaga.

- Muñoz Corbalan, J. M., "Las Atarazanas de Barcelona. Proyecto de reestructuración del sistema cuartelario urbano bajo el reinado de Carlos II!", Actes del Segon Congrés d'Historia Moderna de Catalunya. Barcelona 1988, vol. II, pág. 134. En este artículo se recoge el proyecto existente en el Archivo de Simancas (Guerra Moderna 2999) «Explicación para servir de instrucción a la Fábrica de Quarteles para las Tropas del Rey, assi de Ynfantería, como de Cavallería, que por Regla General se pueden construir en las Plazas de Guerra, y otros Parages de este Reyno, donde se pone Guarnición o Tropas en Quartel'", 
todos los problemas que estas acciones ocasionaban, tanto por el descontento que creaba entre los desalojados como por lo gravoso que resultaba a los Cabildos contribuir al arrendamiento de estas casas, almacenes, mesones o también conventos (a veces los más adecuados por su amplitud), sino también por las obras de acondicionamiento para el alojamiento de la tropa y los gastos que ocasionaba devolver los edificios a su estado primitivo, además de los muchos desperfectos que se habian ocasionado.

Málaga no fue una excepción. Continuamente en las Actas Capitulares se hace alusión a esta situación, y en algunos proyectos sobre construcción o arreglo de cuarteles se insiste en ello. Así en 1770, con objeto de la venida de una compañía del Regimiento de Asturias, se decide dejar "libre y desembarazado" el Mesón de Illescas para que esta tropa se aloje junto a otras compañías del mismo regimiento que ocupaban otros mesones ${ }^{2}$. Y en ese mismo año el Inspector General de Milicias pidió a la ciudad que donase un sitio "cómodo y suficiente» para construir un cuartel para el regimiento de Milicias «respecto del beneficio que se hace al vecindario librándole de la pesada carga de alojamiento". El sitio, que se donaría tras el reconocimiento de los alarifes Juan Garcia y Antonio de Chaes y el Maestro de Obras Miguel del Castillo, era de 3.600 varas cuadradas valoradas en 14.400 ducados, en la playa, junto al castillo de San Lorenzo y delante de las Atarazanas, para el que se realizaron algunos proyectos posteriores ${ }^{3}$. Y lo mismo ocurre en 1775 , al exponer las ventajas sobre una gran actuación en las Atarazanas se indica que "se exonerará al común de alojamientos, de incomodidades a las posadas, de gastos a los Propios y recursos al Real Consejo" ${ }^{4}$.

Málaga, por su situación estratégica como lugar de paso hacia las colonias de Ultramar y desde donde se efectuaba el aprovisionamiento de los presidios africanos, y también cercana a Gibraltar desde donde los ingleses atacaban los envíos comerciales con Europa del Norte y América, obligó a un reforzamiento como plaza fuerte, que ya existía desde fines del siglo XVII al instalarse en la zona de Málaga la Capitanía General de la Costa. Realmente era el puerto el que confería esta importancia a Málaga, tanto desde el punto de vista comercial como militar y provocará a su vez la presencia de tropas a las que hay que alojar ${ }^{5}$.

2 Archivo Municipal de Málaga (A.M.M.) Actas Cap. Vol. 160, año 1770, fols. 15 y v, 24v. y 104.

3 A.M.M. Actas Cap. Vol. 160, año 1770, fols. 24, 48 y 50.

4 A.M.M. Actas Cap. Vol. 165, fol. 663v. Cdo. 3-1-1775.

5 Sobre este tema véase: SÁNCHEZ EsCutia, J. C., "Alojamientos militares en la ciudad de Málaga (1770-1772)", Jábega, n. ${ }^{\circ}$ 50, Málaga, Diputación Provincial, 1985, págs. 48-58. 
Esto llevaria a realizar algunos proyectos de construcción de un cuartel de gran capacidad en el sitio solicitado en la playa o transformar algunos edificios existentes, pero aparte de los conventos, que contaban con amplitud de espacio, aunque evidentemente no demasiado, algunos mesones, los únicos edificios con dimensiones suficientes para instalar cuarteles eran la Alcazaba y las Atarazanas.

Sin embargo, no debía ser muy numerosa la guarnición de Málaga. Una Memoria de un proyecto para cuarteles del Capitán del Regimiento de Infantería de la Princesa, Alfonso Ximénez, realizado en $1774^{6}$, ofrece datos interesantes al respecto. Indica que desde su llegada a Málaga se encontró con problemas de alojamiento para su tropa, pues teniendo sólo cinco batallones de 450 hombres cada uno, y no estando completos ya que había muchos hombres destacados, hubo que alojar a parte de ellos en el convento de Capuchinos, otros en casas particulares y otros tuvieron que mendigar posada pues no podían estar en éstas más de tres días. La causa era que no había habido cuarteles hasta que se decidió hacer de Málaga el depósito de las tropas que debían cubrir las guarniciones de Melilla, Peñón de Vélez de la Gomera y Alhucemas y aunque se utilizó el edificio de las Atarazanas, en el estado en que se encontraba no era suficiente para acuartelar a ningún batallón completo, ocupándose sólo en parte.

Alfonso Ximénez indica que habia hecho diferentes propuestas y proyectos sobre cuarteles, llevado por su tremendo celo, aun sabiendo la poca fuerza que podian tener dada su graduación de simple capitán ${ }^{7}$,

- Archivo Histórico Nacional (A.H.N.) Consejos, leg. 979/6, fols. 3 y ss.

7 En 1776, siendo Capitán del Regimiento de Infantería de la Princesa, se le dio el grado de Ingeniero Ordinario y en 1778 se propuso su ascenso a Ingeniero de segunda y Teniente Coronel (CAPEL, H., y otros, LOS ingenieros militares en España. Siglo XVIII, Barcelona, ed. EU, 1983, pág. 239). Se le comisionó como Ingeniero Voluntario en 1776 pues se consideró la persona idónea, "por su particular habilidad y talento" y por ser "excelente matemático" para dirigir el gran proyecto del Conde de Ricla de organizar la "Colección de Relieves de las Fortificaciones del Reino", muy necesaria sobre todo por la conflictiva situación bélica existente en el norte de África, iniciándose la colección con la maqueta de Cádiz, a la que siguieron las de algunos presidios africanos. (MUÑOz CORBALAN, J. M., "La maqueta de Cádiz (1777-79)", (en prensa), I Jornadas sobre La ingeniería militar y la cultura artística española. Cádiz 1988). Agradezco al profesor Muñoz Corbalán el material que me ha enviado sobre este tema. Véanse del mismo autor: "Las maquetas de Ceuta y de la Bahía de Cádiz (1779). Proyecto de cartografía en relieve para control del Estrecho", (en prensa), I/ Congreso Internacional sobre el Estrecho de Gibraltar. Ceuta 1990. "La "Colección de Relieves de las Fortificaciones del Reino". Essai d'organisation du Cabinet des Plans-reliefs en Espagne pendant le regne de Charles III", en Colloque scientifique Pluridisciplinaire sur les Plans-Reliefs. París 1990. "I plastici e la difesa del territorio spagnolo al tempo di Carlo III. Fallimento e mancata assimilazione del modello francese", Atti dei Colloqui Internazionali "Castelli e Cittá Fortificate". Storia-Recupero-Valorazione. Udine 1990, págs. 1-4. 
pero que no pudo ampliarlos ni los presentó porque continuamente tenia que pasar a Melilla y al Peñón, no obstante pudo adquirir conocimientos sobre los terrenos y los edificios, siendo su primera intención ocupar la playa con cuarteles que pudieran alojar 4.000 hombres. Pero ve, por la experiencia de la guarnición, que los planos de la playa estaban tan errados como todos los que se habian hecho para cuarteles de gran capacidad y realmente Málaga no los necesitaba tan grandes. Señala su situación entre dos departamentos de Marina, que son dos plazas fuertes importantes, Cádiz y Cartagena, por tanto no se usaría este puerto (si así fuera sería en una emergencia porque no había fuertes ni baterías de defensa) y no habia más repuesto de artillería que el necesario para los tres presidios menores, como ya estaba previsto en tiempos de Felipe V. Él alude a que si un cuerpo de infantería de 45 regimientos, cada uno de 953 hombres, forman la guarnición de 46 plazas en el continente y en América, es imposible que se destine más a Málaga para los presidios y esta ciudad no tendría que alojar a mucha tropa, que siempre sería transeunte. Calcula que Málaga, como mucho, necesitaría seis batallones de 476 hombres que en total serian unos 2.800 , de los cuales pasarian a los presidios alrededor de 656, luego en Málaga tan sólo serían necesarios cuarteles que pudieran albergar unos 2.000 hombres de infanteria y tres escuadrones de caballería.

Por tanto es absurdo hacer cuarteles más grandes. Además, éstos al proyectarse en los terrenos de la playa perjudicarian este lugar donde se realizan los embarques de frutos del país con menos gasto que en el puerto, y si por despejar la playa se demoliera el castillo de San Lorenzo, seria mayor perjuicio porque aunque era un hornabeque bajo y muy indefenso en aquellos momentos, era tanto un recinto con una bateria hacia el mar que defendía esa zona como un parapeto para las crecidas del Guadalmedina y habría que edificar otro en otra zona. Por eso él propondrá, como veremos, intervenir en las Atarazanas.

\section{EL EDIFICIO DE LAS ATARAZANAS. ANTECEDENTES HISTORICOS}

Las Atarazanas de Málaga se construyeron bajo la dominación islámica, y aunque se ha especulado que pudiera tratarse de una obra califal parece más plausible situarla entre las destinadas a afianzar el poder político y militar durante la dominación nazari. Ésta se sitúa en Málaga desde 1296, pero según Torres Balbás no será hasta el reinado de 
Yusuf I (1333-1354) cuando se construya el edificio ${ }^{8}$. No obstante el escudo, de formato castellano y con una banda diagonal con la inscripción "Sólo Dios es vencedor, ensalzado sea", que aparece en las enjutas de su puerta principal, conservada, pertenece no al reinado de Yusuf sino al de Mohamed V (1354-1391), por lo que, al menos esta puerta, es obra de la segunda mitad del siglo ${ }^{9}$.

Este edificio, que ocupó un solar aproximadamente cuadrado, fue construido para taller naval, aunque no todos los autores están de acuerdo, limitándolo algunos al uso de almacén. No obstante su fachada sur la describe Münzer en 1492 con seis arcos abiertos para fondear navíos dando acceso a unas naves cubiertas con bóvedas con fajones; un séptimo arco situado más a la izquierda formaba la monumental puerta conservada y conducía a un patio con columnas. En la esquina occidental había una torre cuadrada adosada a la puerta y desde allí partía un muro uniendo con la Torre Gorda o Torre del Clamor, que cerraba la ensenada natural que habia entre ella y el castillo de Genoveses, y servía al almuédano de una mezquita cercana para llamar a la oración ${ }^{10}$.

A principios del siglo xv el edificio estaba junto al mar, señalándolo los marinos cristianos que tripulaban las naves de D. Pedro Niño, conde de Buelma: "por el cabo de Poniente de Málaga es la Tarazana; llega el mar a ella e aún rodeala". Y también lo afirma, a finales de siglo, el cronista Hernando del Pulgar ".

Como el aporte de arenas del río Guadalmedina a partir del siglo XVI fue constante por la desforestación que sufrieron sus márgenes, el mar se fue retirando y las Atarazanas quedaron en zona de tierra por lo que su finalidad no sería la de arsenal y muy pronto empezó a servir como almacén de la más diferente índole y cuartel, hasta que en el siglo XIX, demolida la vieja fábrica surgió en su solar el llamado Mercado de Alfonso XII o de Atarazanas ${ }^{12}$.

B Torres Balbas, L., “Atarazanas hispano-musulmanas”, en Al-Andalus, 1946, pág. 176.

- Aguilar García, M. ${ }^{a}$ D., "El Mercado de Atarazanas", en Baética n. ${ }^{\circ} 6$, Universidad de Málaga, 1983 , págs. 7 y 8.

10 Aguilar Garcia, M." D., Op. cit., pág. 8.

"Gullét Robles, F., Málaga musulmana, Málaga 1880 (ed. facsímil, Diputación de Málaga, 1980), pág. 524 .

12 Agullar Garcla, M.* D., Op. cit., págs. 11 y ss. 
Las Atarazanas tuvieron muy pronto un uso militar habiéndose instalado en ellas diferentes cuarteles, para caballería e infantería, entre ellos el de Asturias y el de la Princesa. En el siglo XVIII se realizaron diferentes proyectos de reforma, reseñándose en 1752 la intervención del arquitecto trinitario Fray Miguel de los Santos que por su costo debió ser obra menor ${ }^{13}$. A finales de ese mismo año el arquitecto y profesor de matemáticas, Ambrosio Arias, realizó obras de mayor consideración en el mismo edificio, tanto en la zona que ocupaban los cuarteles de cabaliería como en el del regimiento de Asturias ${ }^{14}$.

Como ya indicamos, desde 1770 se había planteado la construcción de un cuartel de nueva planta en la zona de la playa y en 1773, el Intendente de Granada a través de la Junta de Propios y Arbitrios de la Ciudad solicitó diferentes proyectos para que el Consejo decidiera si era más favorable emprender la construcción de nuevos cuarteles o se arreglaban las Atarazanas, completándose los proyectos con informes sobre disposición del edificio, regimientos que las ocupan, gastos que hacen las tropas y coste de su reconstrucción ${ }^{15}$. Un plano de 1760 nos ofrece claramente el sector de la bahía de Málaga sobre el que se pretenderá intervenir en estos años, señalando las Atarazanas ( $Y$ ), el castillo de San Lorenzo (B) y la zona de playa que queda entre ellos, donde se proyectarían los nuevos cuarteles ${ }^{16}$ (Fig. 1).

Se realizaron algunos proyectos desde la esfera militar pues en abril de 1773 se fecha el del ingeniero D. Francisco Gózar, cuya propuesta de intervención sobre las Atarazanas suponía un acuartelamiento con capacidad de 1.080 plazas ${ }^{17}$ (Fig. 2).

La ciudad acordó, en octubre de 1773 , que se cumplieran las indicaciones del Intendente encargándose el reconocimiento, plan del terreno y edificio de las Atarazanas a los maestros Antonio Ramos, arquitecto Mayor de la Catedral, Félix de Rojas que lo era de albañilería y alarife y Felipe Pérez el Menor, también maestro de albañilería, no olvidando en sus informes los sitios que pertenecen en el mismo terreno a la ciudad y

13 A.M.M. Actas Cap., vol. 143, año 1752, fol. 99v. Morales Folguera, J. M., «Historia de las obras públicas en Málaga en el siglo XVIII l', Jábega, n..$^{\circ}$. Málaga 1985, pág. 63.

${ }^{4}$ A.M.M. Actas Cap., vol. 143, año 1752, fols. $509,520,557$ y 567.

15 A.M.M. Informes en Actas Cap., vol. 165, fols. 659 y ss., Cdo. 5-10-1775.

${ }_{16}$ A.H.N. Consejos, leg. 34.169, fol. 289.

17 Plano procedente del Servicio Histórico Militar, 3004 (Vid: Biblioteca Diputación Provincial, Sala Andalucía). 


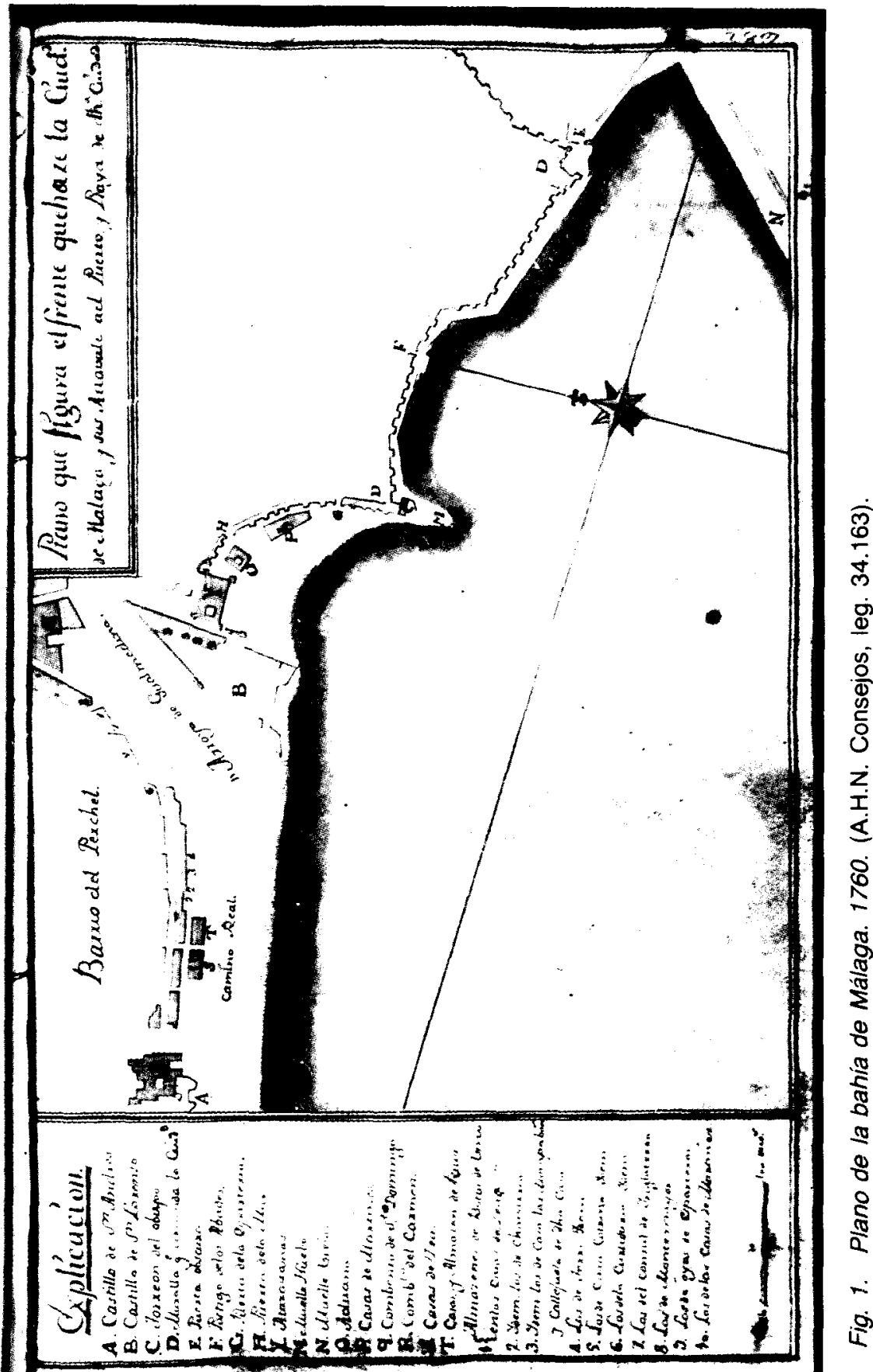




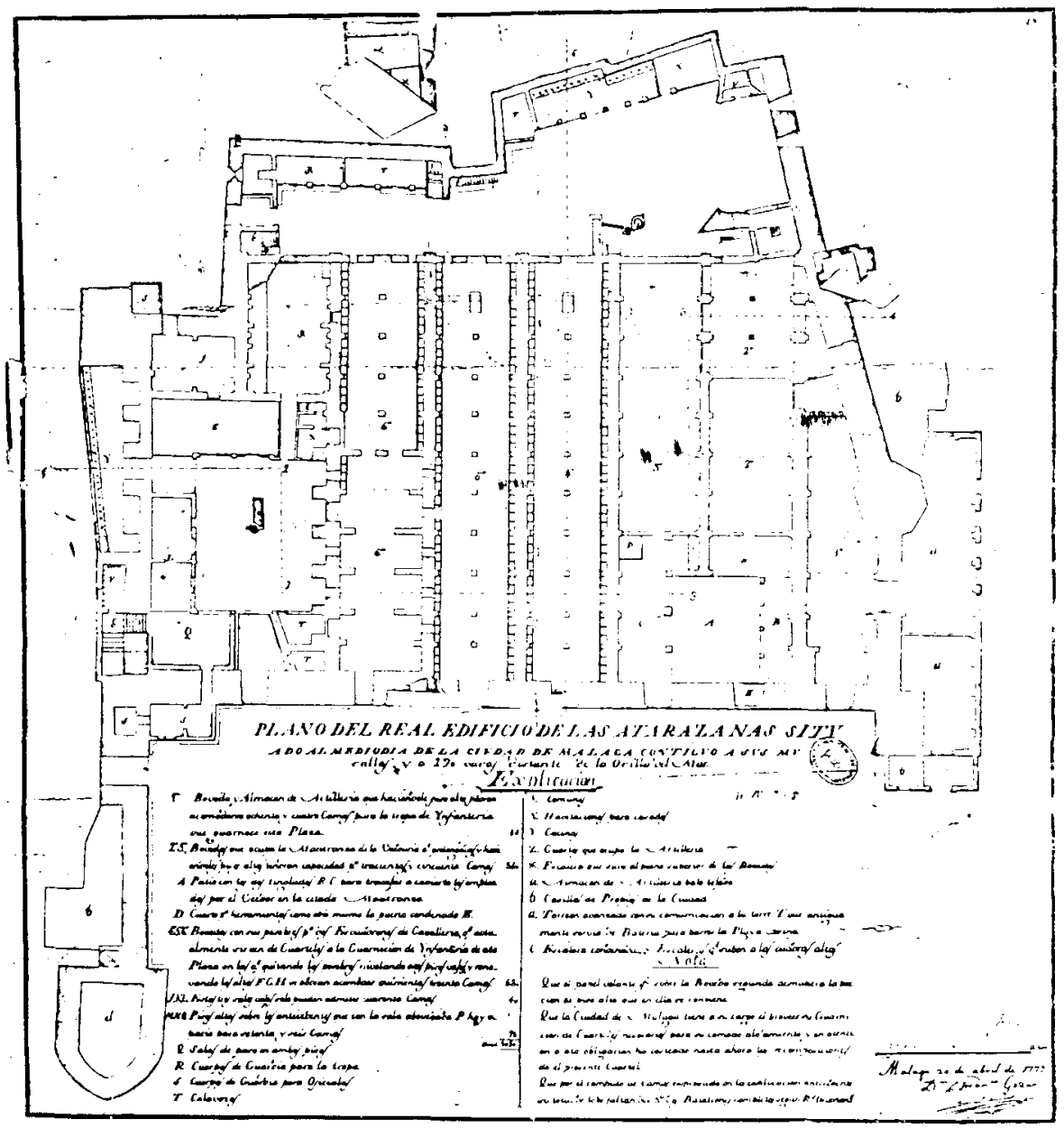

Fig. 2. Proyecto de cuartel en las Atarazanas de Málaga. Francisco de Gózar. 1773. (Servicio Histórico Militar).

el valor por venta u otro tipo de enajenación, teniendo en cuenta que se encontraban en el mejor sitio de la ciudad.

En abril de 1774 presentaron éstos su valoración que firma también el maestro de carpintería y alarife de la ciudad Antonio de Chaes ${ }^{18}$. El

18 A.M.M. Actas Cap., vol. 165, año 1775, fols. $622-653$ (el informe está fechado en abril de 1774). 
proyecto, firmado por Ramos y Rojas, se ajusta a un plano, perfiles y elevación que no se encuentran junto a los informes, y supone una fuerte actuación sobre el edificio existente, demoliéndose parte de él y reconstruyéndose. Esta obra se tasa en 1.857.547r., aunque como era un edificio viejo se calcula un tanto para imprevistos, pero deduciendo la cantidad que importa la venta de los derribos, el costo total presentado es de 1.926.514r. El proyecto se completa con el cálculo de valoración de las Atarazanas y lo que rentaria si se hicieran los cuarteles en otro lugar, importando su solar, fábrica y materiales de derribo 1.338.806r., que firman, además de los anteriores, Felipe Pérez y Antonio de Chaes.

Los planos y valoraciones los remitió la Junta de Propios al Rey por vía de Guerra y al Consejo de Castilla, pero dada la importancia del expediente se decide informar rápidamente a la ciudad para que vaya aprontando los fondos.

En Cabildo de 19-12-1774 se vieron los certificados y planos y se acordó que pasasen a Felipe Pérez el Mayor ${ }^{19}$ y Miguel del Castillo, maestros de obras de la ciudad para que los reconocieran y emitieran su informe, quienes lo hacen también sobre otro proyecto de construcción de cuarteles de nueva planta en la explanada que queda entre el castillo de San Lorenzo y la Torre Gorda, firmado por Diego de Robles.

Pérez y Castillo en enero de 1775 solicitaron un plazo de tres meses para emitir su informe dado que tenian que hacerlo a la vez que sus trabajos particulares y el proyecto de Robles era más dificultoso por faltarle el cálculo y algunos detalles de delineación, sin embargo, debieron pagárselo como tal ya que lo presentaron en el mes siguiente y es a

19 En estos informes se cita a Felipe Pérez el Menor, maestro de albañilería, y después al Mayor, arquitecto. Los maestros Felipe Pérez son una saga de arquitectos que llena una parcela importante de la arquitectura y la ingenieria en Málaga y su territorio durante el siglo XVIII. El primero de este nombre que viene a Málaga es Felipe Pérez Conde, natural de Añober de Tajo (Toledo), que se documenta en 1720 como encargado de las obras del dique oriental del puerto y murió entre 1759-60. En las escrituras e informes se refieren a él como Felipe Pérez el Mayor dado que su actividad coıncide en parte con la de su hijo al que se le cita como el Menor. Éste tuvo cargos importantes siendo maestro mayor de las obras del Muelle, alarife de la ciudad, agrimensor con título de Granada y maestro mayor de fábricas menores por lo que intervino en obras de carácter religioso, y consta que murió en 1776 (Сamacho Martinez, R., y Romero Martinez, J. M.", La ermita del Cristo de Zamarrilla de Málaga, Col. Asuntos de Arquitectura "El Barroco". Málaga, Colegio de Arquitectos, 1986, págs. 4-5). Este último maestro es el que aparece en los proyectos sobre las Atarazanas como el Mayor, porque también trabajaba entonces en la ciudad otro maestro del mismo nombre al que se le cita como el Menor, quien firma el proyecto con Ramos. 
través de éste como podemos conocer este último proyecto y algunos detalles formales del de Ramos.

Éste, lo van a rechazar totalmente por su elevado costo y por su disposición formal. Además parecen dudar que sea de Ramos, pues se refieren a él como «los planos, perfiles y alzados ejecutados unos por Diego de Robles, y los otros (al parecer) por Antonio Ramos, estos firmados del susodicho", citándolo más tarde como el proyecto de "D. Antonio Ramos y consortes". Cabría la posibilidad de que lo único que pusiera Antonio Ramos aqui fuese su firma porque no tuviese tiempo para realizar el proyecto pero al menos avalarlo con su prestigio, aunque no sivió de nada y es un punto negativo en su brillante historial como arquitecto.

Además de rechazarlo porque la intervención en las Atarazanas es muy cara, también lo hacen porque se ocupa la extensión que hay ante ellas hasta formar línea con el ángulo entrante que causa la Torre Gorda, creando una pantalla que es perjudicial tanto para la Aduana como para el acceso a la ciudad por la Puerta del Mar, sobre todo porque ésta se halla en el fondo de una plaza cuadrada y ante ella "se hacía una figura bastante horrenda en el sitio más precioso de la ciudad donde están las entradas principales". Además consideran poco útil hacer los cuarteles en las Atarazanas por su elevado costo, ya que según sus cálculos se tendría que aumentar el presupuesto a 3.275 .320 r. $17 \mathrm{mrs}$. y además se pierden los 27.200r. que se sacaría por su arrendamiento.

Sí aceptan el proyecto de Robles que les parece beneficioso para la ciudad ya que su costo es casi la mitad del anterior, 1.700 .000 r más o menos, y además valoran mucho la fábrica que es «hermosa, de bella simetria", en especial en la parte que se agrega en "la fachada de las Atarazanas volviendo el ángulo que va a la Torre Gorda». Este proyecto no afecta a las Atarazanas, ya que se propone la construcción del cuartel en la explanada que hay ante ella, junto al castillo de San Lorenzo y previa la destrucción de la Torre Gorda (lo que aprueban los informantes), además en los portales se puede hacer la Pescadería y Panadería (de las que aún carece la ciudad y ésta lo había propuesto ya que la construcción del cuartel suponía la desaparición de la casilla donde se vendia el bacalao), reservando los pisos primero y segundo para los cuarteles tanto de Caballería como de Infantería que darían cabida a 52 compañías y 400 caballos. Además valoran mucho que lleve anejo este proyecto la construcción de una plaza de toros cuyo uso amortizará en pocos años el coste de su fábrica y los cuarteles, aunque ésta por encontrarse en el centro no se ve en el plano y no la pueden juzgar, pero siempre al ir edificando se le podría dar diversa disposición. 
Leídos estos informes ${ }^{20}$, se acordó devolverlos a los maestros para que presentasen el costo que pudiera tener la plaza de toros separada del conjunto de los cuarteles con la Pescadería y Panadería, los cuales valoraron éstos en 1.273.476r y la plaza de toros en 426.524r. Pero no hacen nuevo proyecto aunque si precisan que, al encontrarse la plaza en el centro, si se prescindía de ella se acortaría la línea de fachada quedando más sitio para la ciudad (aproximadamente 40 varas de fachada de las señaladas en el plano).

Dada la situación económica de la ciudad, el Cabildo aceptó el plan de Robles sin la plaza de toros, por el ahorro que suponía de $\mathbf{4 0 . 0 0 0}$ ducados; además asi se dejaban libres las Atarazanas a beneficio de los Propios y para poder acomodar a otras tropas ${ }^{21}$.

Previamente se había realizado un informe sobre la Alcazaba ya que un capitular propuso estudiar la posibilidad de acomodar las tropas en la Alcazaba, para lo cual ya se habian hecho estudios en 1759, porque pensaba que tenía mayor capacidad y la superioridad lo aprobaría por su menor costo, además convenia que la explanada de delante de las Atarazanas quedase como sitio despejado y siguiera sirviendo para ejercicio de la tropa. La ciudad acordó que los maestros Pérez y Castillo estudiasen los antecedentes y sus informes no fueron favorables, precisamente por la escasa capacidad del edificio ${ }^{22}$.

En octubre de 1775 la ciudad aprobó el plan de Robles ${ }^{23}$, pero las obras no se emprendieron inmediatamente porque para costearlas sólo había el sobrante de los Propios que estaba aplicado a la redención de censos, $y$ otras circunstancias hicieron que este proyecto no fuera nunca una realidad.

En esta actividad hay que citar otro proyecto, citado más arriba, que se conserva con su planimetría y fue realizado por el Capitán del Regimiento de Infantería de la Princesa Alfonso Ximénez, quien lo envió directamente al Consejo de Castilla ${ }^{24}$. Como ya vimos, había proyectado varios cuarteles pero no los había presentado, pero ahora razones de orgullo y prestigio profesional le obligan a ello. Señala que cuando volvió de su misión en el Peñón y se enteró de que el Consejo mandaba a los arquitectos civiles de la ciudad formar los proyectos para cuarteles no

\footnotetext{
2o A.M.M. Actas Cap., vol. 165, fol. 664, Cdo. 16-2-1775.

21 A.M.M. Actas Cap., vol. 165, fol. 666, Cdo. 27-3-1775.

22 A.M.M. Actas Cap., vol. 165, fol. $485 v$ y 486, Cdo. 3-8-1775.

23 A.M.M. Actas Cap., vol. 165, fol. 670, Cdo. 2-10-1775.

24 A.H.N. Consejos, leg. 979/6. Planos Consejos, n. ${ }^{\circ} 145,146$ y 147.
} 
sintió ningún reparo en presentar los suyos «quizá con algún acierto por ser la fábrica y su profesión militar» ${ }^{25}$. Hace una crítica de aquellos proyectos de cuarteles no realizados por expertos que van en perjuicio del ejército. Realmente más que una Memoria de un proyecto es toda una ordenanza militar y expone un planteamiento de la situación social del ejército. Para disponer los pabellones de oficiales se remite a Belidor y a otros jefes militares que siempre los situaron cerca de la tropa, no obstante le parecen mejor los cuarteles construidos en Barcelona y Reus que los de Belidor y de los ingleses, y los toma como ejemplos.

Por considerar que Málaga no albergaría nunca una gran guarnición no presenta el plano para cuarteles en la playa para 4 o 5.000 hombres y realiza un proyecto de actuación sobre las Atarazanas, derribando algunos torreones, levantando con estos materiales otras fábricas y sirviéndose de lo ya construido.

Además de la Memoria presenta cinco planos con sus explicaciones: En el primero manifiesta el terreno de los arsenales tal como estaban entonces ${ }^{26}$. El $2 .^{\circ}$ es igual que el anterior pero con diferentes colores señala lo que se va a demoler, lo que se ha de construir desde cimientos y las fábricas que podían servir. El plano $3 .^{\circ}$ presenta la propuesta de ampliación con dos pequeñas alas paralelas para pabellones. El $4 .^{\circ}$, que es continuación del anterior, propone, entre aquellas dos alas la construcción de una plaza de toros que queda ante la fachada de las Atarazanas y serviría para pabellones, cuadras, patio, teniendo en su fachada la Pescadería y la Panadería, oficinas públicas que faltaban en Málaga, quedando asi dos plazas o patios amplios para los ejercicios de la tropa. $Y$ cuando llegase la ocasión, una de esas plazas, la que tiene forma elíptica, serviría de plaza de toros y así no se maltrataría la plaza pública, tanto por lo que sufrian sus fábricas como por las desgracias que ocurrian al montar los andamios y servirse de ellos. El $5 .^{\circ}$ es un croquis de la zona con la propuesta completa. (Figs. 3,4 y 5)

Con este proyecto sólo se haría nueva la plaza de toros, invirtiendo en esta obra el gasto de las oficinas públicas (Pescaderia y Panaderia), no levantando una fábrica costosa que iria en perjuicio de las Rentas Reales y se lograrian ventajas para el comercio y utilidad del pueblo. Finalmente describe el cuartel que ha proyectado, la capacidad de las casas, las diferentes salas, cuerpos de guardia, dos capillas, piezas para armamento, comunes, cocinas abundantes, etc., todo ello sin añadir un

25 A.H.N. Consejos, leg. 979/6, fol. 6.

26 Este plano no se encuentra, pero como él mismo indica es igual al segundo. 


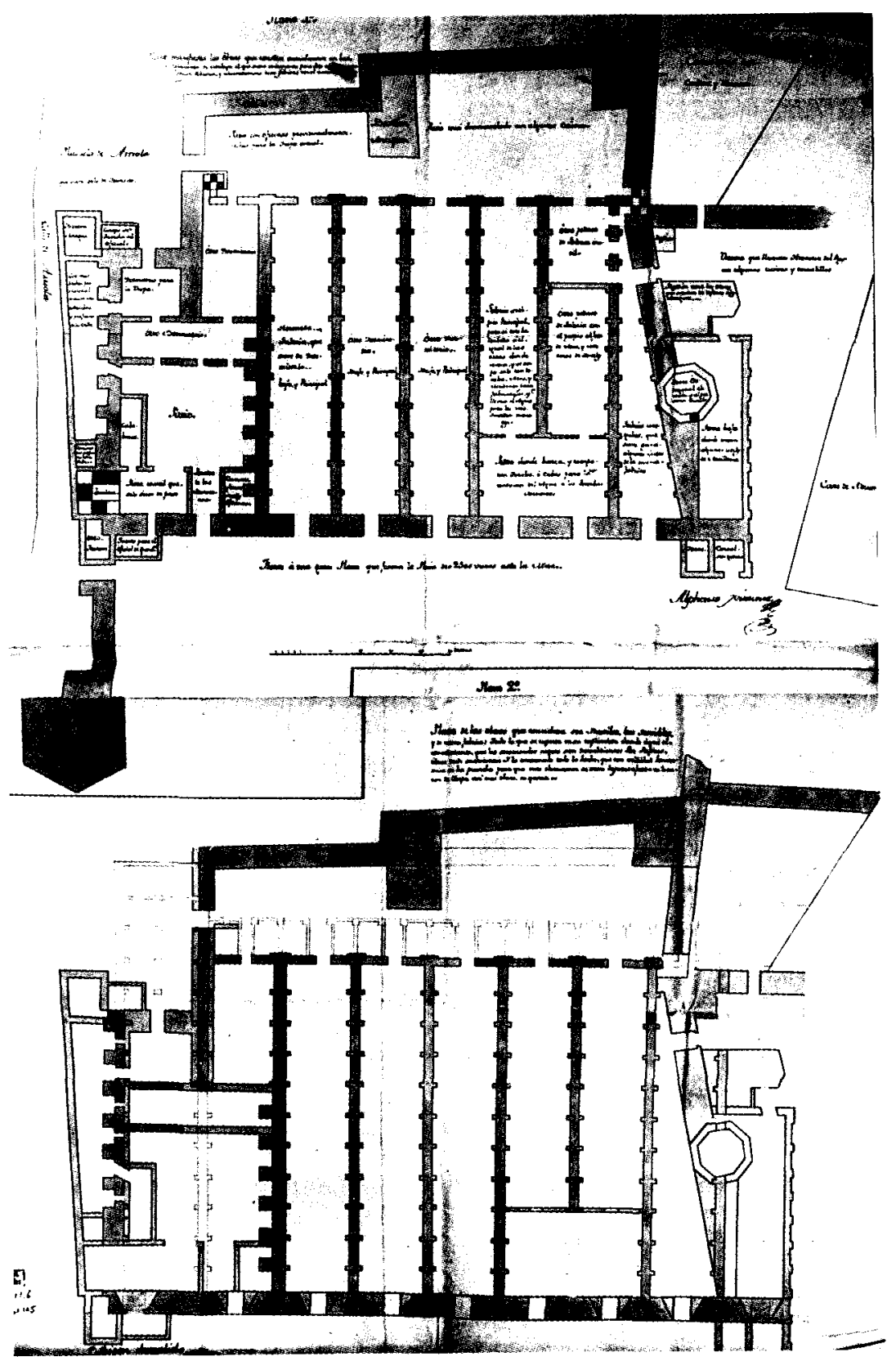

Fig. 3. Proyecto de cuartel en las Atarazanas de Málaga. Alfonso Ximénez. 1774. Planos $2^{\circ}$ y $4^{\circ}$ (A. H. N. Consejos, plano n. ${ }^{\circ} 145$ ). 


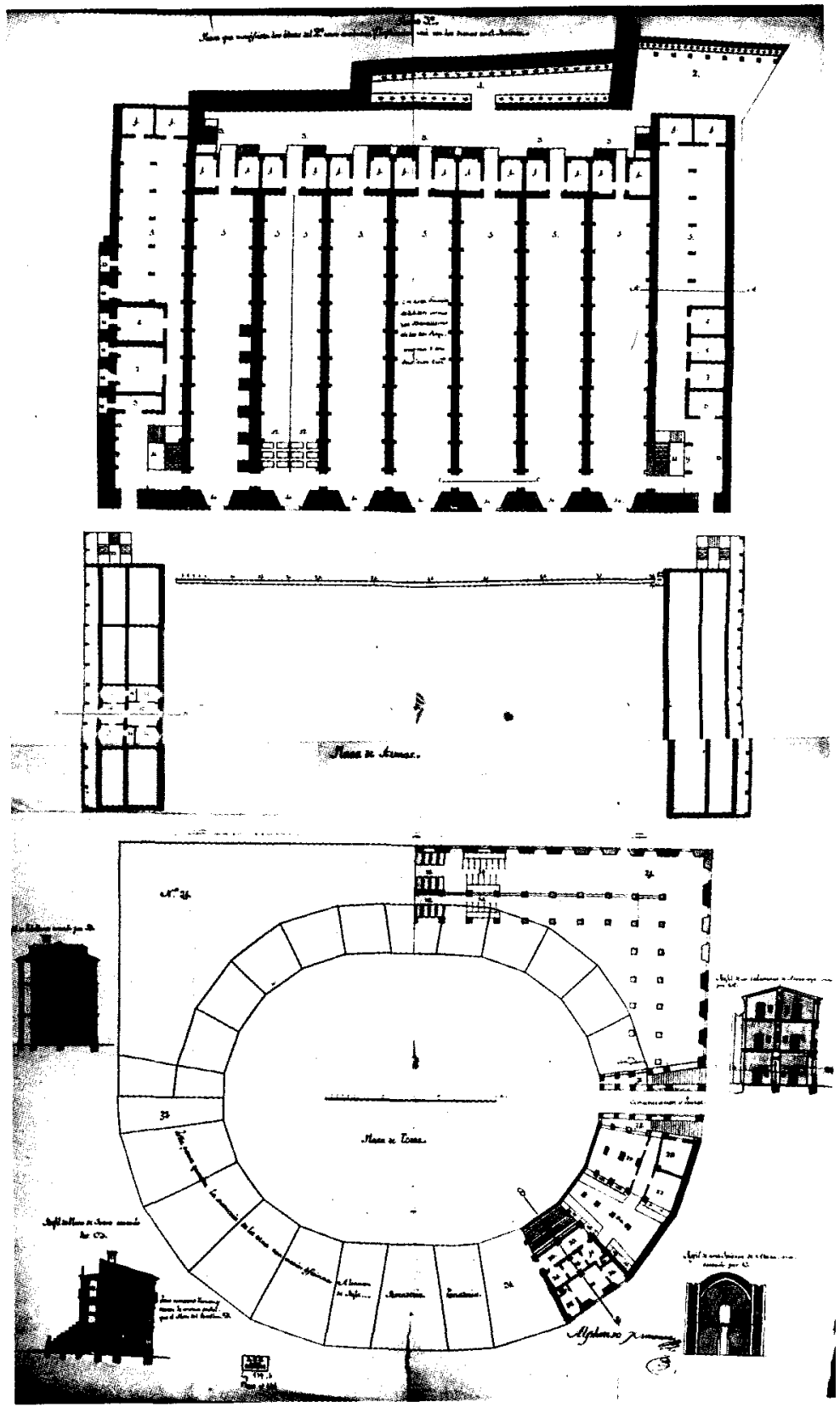

Fig. 4. Proyecto de cuartel en las Atarazanas de Málaga. Alfonso Ximénez. 1774. Planos $3 .^{\circ}$ (A. H. N. Consejos, plano n. $\left.^{\circ} 146\right)$ 


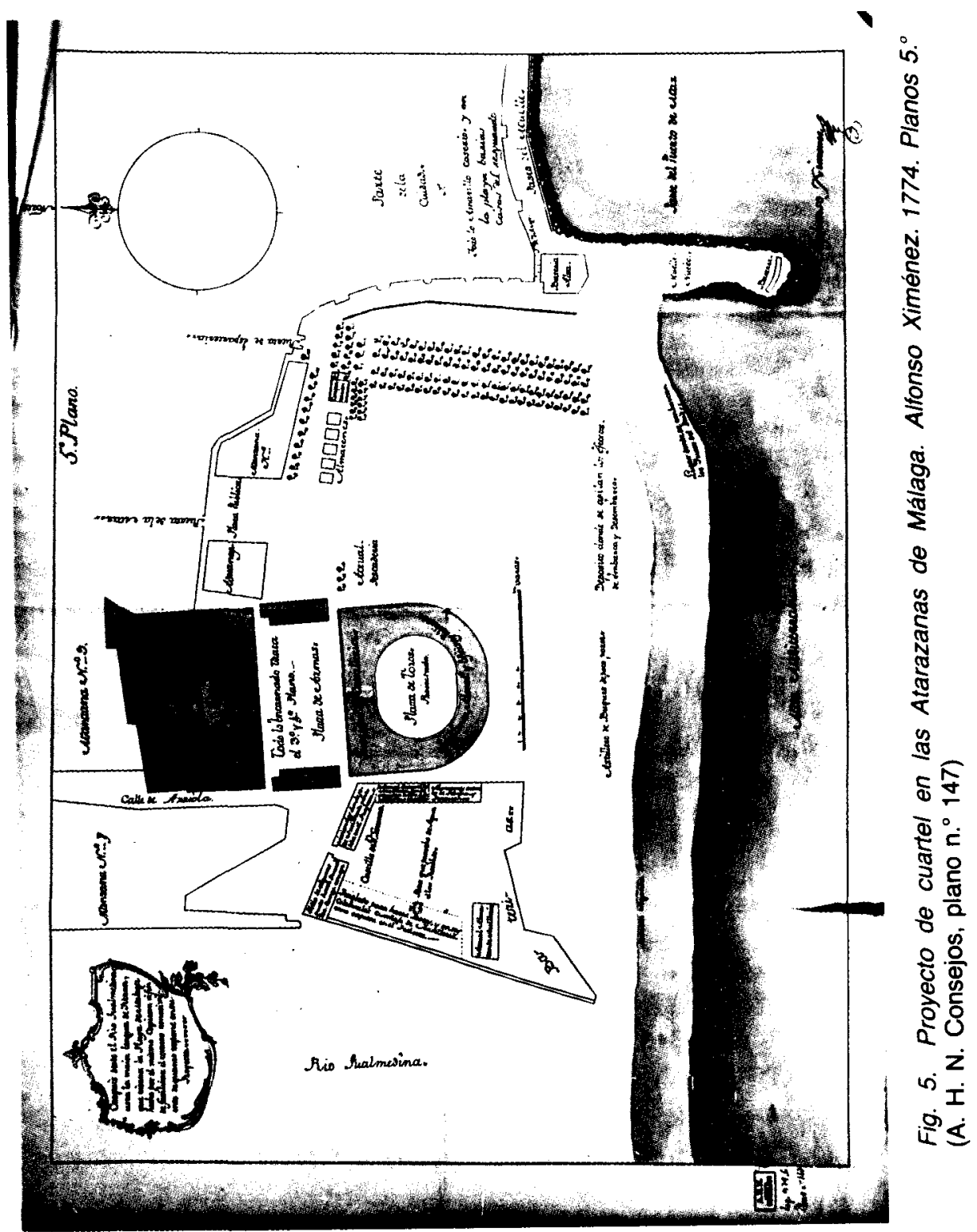


piso ni otros cuerpos en el frente y sólo con el gasto de demoler unas obras para formar otras. Únicamente se aumentan dos alas de pabellones para sargentos y oficiales, muchas "guardillas» para soldados casados y debajo de las escaleras obradores y viviendas para los armeros. En lo que sería plaza de toros estaban previstas cuadras para más de trescientos caballos y cuartos para sus jinetes y jefes, además de otras dependencias necesarias, diseñado todo de modo que no fuesen incompatibles cuando hubiera funciones de toros.

Con este proyecto deja libre la playa y no se toca el castillo de San Lorenzo, tan sólo se aumenta con un "parque» formado con las columnas de las zonas demolidas de las Atarazanas para que pudieran trabajar a cubierto los toneleros que hacian las botas para llevar el agua a los presidios, quedando también a cubierto el pozo. Asimismo dispone una nueva ordenación para el castillo de San Lorenzo que aumentaría su capacidad.

En cuanto al costo, no quiere exponerse a darlo por lo fácil que es errar calculando sobre obra vieja, pero propone que si se han de gastar dos millones para las obras de los otros cuarteles grandes, se saque por proporción el que él propone que siempre será de menos costo.

Enviado el proyecto a Madrid, alli se decide, en enero de 1775 que se una al expediente con los otros proyectos para remitir a D. Marcos Viedma, Comisario de Guerra, y después al fiscal, quien lo envió a Ventura Rodríguez para su información, la cual no consta en el expediente.

De los proyectos analizados, el de Diego de Robles, personaje bastante desconocido, queda muy poco perfilado ya que lo conocemos a través de informes indirectos y en éstos se quejaban de su falta de detalle; pero en cualquier caso no afecta a las Atarazanas. El proyecto de Ramos, tan denostado en el informe de los expertos requeridos, supone una transformación sustancial de las Atarazanas, detallada en la documentación, pero faltan los planos. El de Alfonso Ximénez aunque no explica la obra con su respectivo costo tanto como el anterior, al menos conserva los planos y estas imágenes ofrecen mayor número de detalles; además es el más completo ya que sobre la actuación en las Atarazanas introduce el elemento del patio de maniobras convertible en plaza de toros, novedad que los expertos y la ciudad hubieran apreciado como ya se hizo en el proyecto de Robles.

Pero evidentemente no se llevaron a cabo ninguno de estos proyectos. Precisamente en 1786 el mismo Alfonso Ximénez, entonces Teniente Coronel de Ingenieros con plaza en Málaga, traza un ambicioso proyecto para terminar con las avenidas del Guadalmedina y la situación de las 
Atarazanas y castillo de San Lorenzo no ha cambiado con respecto a la que tenían en $1774^{27}$. Será un siglo más tarde, a partir de 1875 , fecha en que el arquitecto municipal Joaquin Rucoba firma el proyecto del nuevo mercado y ya demolido el viejo edificio, cuando se consolide un cambio de uso y de imagen para las viejas Atarazanas.

27 Perez de Colosia Rodriguez, M." I., "El Guadalmedina en el siglo xVill», en Baética, n. ${ }^{\circ}$, Universidad de Málaga, 1982, págs. 171. El informe se encuentra manuscrito en el Archivo de la Catedral de Málaga, leg. 646, n. 27. 
